\title{
УДК 378.091.64:811.133.1 \\ EXPLOITER LA DIMENSION CULTURELLE DE LA PUBLICITÉ ICONIQUE POUR L'ENSEIGNEMENT INTERCULTUREL DES FUTURS ENSEIGNANTS DE FLE
}

\author{
Rusnak D. A. \\ dianarousnak@gmail.com \\ Université Nationale Yuriy Fedkovitch de Thervivtsi \\ Дата надходження 01.10.2018; Рекомендовано до друку 01.12.2018.
}

Руснак Д. А. Чернівецький національний університет імені Юрія Федьковича

Опрацювання культурного аспекту іконічної реклами в процесі формування у майбутніх учителів / викладачів французької мови міжкультурної комунікативної компетентності

Анотація. Постановка проблеми. Міжкультурна комунікативна компетентність є однією 3 цільових для формування у студентів - майбутніх учителів / викладачів іноземної, зокрема французької, мови. 3-поміж сучасних засобів формування міжкультурної комунікативної компетентності виокремлюються різноманітні автентичні матеріали, з-поміж яких особливе місце посідає реклама. Мета статті проаналізувати культурну складову іконічної реклами французької преси з метою їі (реклами) використання в процесі формування міжкультурної комунікативної компетентності. Результати дослідження. В статті досліджено різні жанри іконічної реклами французької друкованої преси: інформативну рекламу, класичну рекламу, сучасну рекламу й пост-модерністську рекламу. Наголошено на перевагах і недоліках використання кожного жанру в освітнього процесі. Проаналізовано культурні коди, присутні в кожному рекламному жанрі, запропоновано шляхи їх аналізу в процесі формування у майбутніх учителів / викладачів французької мови міжкультурної комунікативної компетентності. Відповідно до семіотичному підходу пропонується аналізувати рекламу на трьох рівнях: лінгвістичному, іконічному й символічному (культурному) з метою покращення іï розуміння студентами та сприяння формуванню у них культурних знань - основного складника міжкультурної комунікативної компетентності. Висновки. Зроблено висновок про те, що найменш адаптованою для освітнього процесу є сучасна реклама, мета якої - викликати задоволення, а найефективнішою для формування міжкультурної компетентності може бути пост-модерністська (етична) реклама, мета якої - заставити думати й сформувати громадянську позицію. Саме використання останньої в освітньому процесі уможливить урізноманітнення культурного змісту навчання французької мови й культури у закладі вищої освіти.

Ключові слова: іконічна реклама; міжкультурна комунікативна компетентність; майбутній учитель / викладач; французька мова

Руснак Д. А. Черновицкий национальный университет имени Юрия Федьковича

Использование культурного аспекта иконической рекламы в процессе формирования у будущих учителей / преподавателей французского языка межкультурной коммуникативной компетентности. Анотация. Межкультурная коммуникативная компетентность является одной из целевых для формирования у студентов - будущих учителей / преподавателей иностранного, в частности французького, языка. Среди современных средств формирования межкультурной коммуникативной компетентности выделяются разнообразные аутентичные материалы, среди которых особое место занимает реклама. В статье проанализированы разные жанры иконической рекламы французской печатной прессы. Акцентированы преимущества и недостатки использования каждого жанра в процессе обучения. Проанализированы культурные коды, присутствующие в каждом рекламном жанре, предложены пути их анализа в процессе формирования у будущих учителей / преподавателей французского языка межкультурной коммуникативной компетентности в контексте семиотического подхода. Сделан взвод о том, что наименее адаптированной к процессу обучения является современная реклама, а наиболее эффективной может быть пост-модернистская (этическая) реклама. Использование последней позволит разнообразить культурное содержание обучения французскому языку и культуры в вузе.

Ключевые слова: иконическая реклама, межкультурная коммуникативная компетентность, будущий учитель / преподаватель, французский язык. 
Rusnak D. A. The National University Yuri Fedkovitch of Chernivtsi

Cultural dimension of iconic advertising in intercultural education of prospective French teachers / lecturers Abstract. Intercultural communicative competence is one of the key goals in students' intercultural education: prospective teachers / lecturers of foreign, especially the French language. Among modern means of intercultural communicative competence formation authentic materials are sorted out. We consider advertising as an effective method of foreign language and culture teaching. As a result of our research we distinguish the types of authentic iconic advertising: information, classic, modern and post-modern advertising. We analyze the cultural dimension of each kind of advertising and discuss their pros and cons. We propose to analyze the iconic advertising in tree levels: linguistic, visual and symbolic in conformity with a semiotic approach. We conclude that modern advertising is less adapted for educational process, but the post-modern advertising could be very effective for intercultural communicative competence developing.

Keywords: iconic advertising; intercultural communicative competence; prospective teacher / lecturer; French language.

Le problématique. L'enseignement de la langue est indissociable de celui de la culture. Comme le démontre L. Porcher, la langue est tout entièrement marquée de civilisation, d'une part parce qu'elle est un produit socio-historique et d'autre part dans la mesure où elle est toujours d'abord une pratique sociale (Porcher, 1986, p. 33). Par conséquent, la dimension interculturelle est au centre de l'enseignement des langues vivantes, en particulier du français langue étrangère (FLE) dans l'environnement institutionnel en Ukraine.

La démarche interculturelle représente un atout dans l'enseignement / apprentissage de la culture du pays cible parce qu'elle vise l'enseignement de la langue et celui de la culture d'une manière inséparable. Or, la prise en compte de dimension interculturelle dans la classe de langue demande une réflexion sur les matériels et les contenus d'apprentissage. Pour ce qui nous concerne, les documents authentiques, et surtout les documents médiatiques constituent un support privilégié pour le travail sur la compétence de communication interculturelle parce qu'ils permettent l'imprégnation dans l'environnement culturel où l'on parle la langue cible.

En effet, les documents authentiques sont depuis longtemps sollicités dans la classe de FLE pour motiver les apprenants, susciter leurs intérêts et les faire communiquer, mais surtout pourleurfaire découvrir une culture étrangère.

Pourtant, dans le processus de l'enseignement / apprentissage du FLE à l'école supérieure, au niveau des pratiques de classe apparait un problème de l'exploitation des médias en tant que documents authentiques, surtout en première et deuxième années d'études. Attachés au manuel et ayant peur de s'écarter du programme, les enseigòants utilisentt rarement les matériels supplémentaires, en prévoyant le travail sur les documents d'actualitépour plus tard. En fait, l'intégration des médias en classe de langue, selon le Programme, est obligatoire à partir de troisième année et les cours de civilisation française n'ont lieu qu'en quatrième année. Au niveau débutant d'études universitaires (en première et deuxième années) l'enseignement se voit plutôt systémique, l'accent est mis sur les aspects linguistiques de la langue étrangère (grammaire, lexique, phonologie).

Alors, les questions se posent: - Comment optimiser l'exploitation des doculents d'actualité lors des cours de langue pratiques en première /deuxième années d'études? Quels contenus d'apprentissage sont à proposer pour l'enseignement interculturel sans s'écarter trop du Programme d'enseignement institutionnel? Quel(s) document(s) médiatique(sà sera(ont) le(s) plus efficace(s) pour l'enseignement interculturel des futurs enseignats de FLE lors de cours de langue pratiques au niveau débutant d'études universitaires?

Nous supposons que la publicité peur s'avérer un matériel supplimentaire efficace aux contenus socioculturels variés qui permettrait de développer une compétence de communication interculturelle chez les futurs enseignants de FLE.

L'analyse des dernières recherches. Il faut dire que l'exploitation de la publicité en classe de langue n'est pas une pratique nouvelle. Une série de recherches en didactique du FLE y sont consacrées 
(А. Г. Дульянінова, Ж. І Ігумнова, Т. В. Карамишева, А. І. Иванченко, П. Ю. Мельник,. Д. А. Руснак, M. Boiron, B. Bulgari, M.-F. Narcy-Combes et d'autres). En particulier, dans nos recherches précédentes nous avons étudié la publicité dans l'enseignement de la grammaire (Руснак 2005), de la compréhension orale (Руснак 2015) et, de plus, nous avons fait les premiers pas dans l'étude de la publicité en tant que support dans l'enseignement interculturel des futurs enseignants de FLE en y étudiant les stéréotypes qui véhiculent dans les sociétés française et ukrainienne (Руснак 2017; Rousnak 2018).

Pourtant, malgré la diversité des partiques pédagogiques, la dimension culturelle de la publicité en vue de son exploitation lors des cours de langue pratiques dans l'environnement institutionnel en Ukraine reste à étudier d'une manière plus détaillée. Il est à noter qu'en général, dans la classe de langue, la publicité, en tant que document authentique,est exploitée comme support pour le développement des compétences linguistiques et communicatives, tandis que l'enseignement de la culture se passe, en plusieurs cas, plutôt d'une manière implicite.

Le travail présent se pose comme objectif d'étudier la dimension culturelle de la publicité iconique afin d'exploiter ses contenus lors des cours de langue pratiques en première / deuxième années d'études universitaires. En premier lieu, nous examinerons les genres publiictaires d'un point de vue sociolinguistique et en dégagerons celles qui sontles plus compatibles avec le processus d'enseignement / apprentissage en classe de langue. Ensuite, nous analyserons les contenus culturels de la publicité qui serviront de support à l'enseignement interculturel des futurs enseignants de FLE. Finalement, nous proposerons une pisted'exploitation de la publicité iconique en présentant un parcours de compréhension selon une démarche sémiologique quifavoriserait le développement de la conscience interculturelle chez les étudiants.

Notra travail se fonde sur les recherches dans les domaines sociolinguistique, sémiologique,de communication interculturelle.Le corpus de notre recherche constitue la publicité iconique trouvée dans la presse écrite francophone ainsi que sur Internet.

Les résultats essentiels de la recherche. Dans le processus d'enseignement / apprentissage du FLE à l'école supérieure les étudiants s'acquièrent graduellement la compétence de communication interculturelle (CCI) qui se voit comme une capacité à communiquer avec les représentants d'autres cultures en créant les relations harmonieuses dans de différentes situantions culturelles (J.-C. Beacco, M. Byram, E. Elizarova, G. Zarateet d'autres).

D'une manière générale, on peut inclure dans la CCI (M. Byram 2002; Il. Lázár et M. HuberKriegler 2007): la composante cognitive: les savoirs (connaissances socioculturelles de la culture maternelle $(\mathrm{C} 1)$ et de la culture cible $(\mathrm{C} 2)$ ); la composante pragmatique: les savoir-faire (savoir-faire et apptitudes de communication en oral et en écrit); la composante affective: les savoir-être (comportements et attitudes).

Il faut souligner que la notion clé de la CCI, ce sont les connaissances des deux cultures (C 1 et $\mathrm{C} 2$ ) qui permettent la prise de conscience interculturelle. C'est pourquoi dans le cadre de notre recherche, nous nous intéresserons à la composante cognitive - les savoirs - qui est fondamendale pour la CCI et dont la formation dépend des contenus culturels d'apprentissage mis en disposition des étudiants.

Il est évident que dans la classe de langue hors du pays cible ces contenus sont introduits par le biais des documments authentiques parmi lesquels la publicité nous semble n'avoir quedes avantages. Puisque la publicité fonctionne dans la société française, elle reflète la représentation du monde de cette société, ses valeurs, traditions, orientations et histoire (Barthes 1985). De ce fait, la publicité est riche en contenus culturels qui peuvent être étudiés en classe de FLE.

La pratique d'exploitation de la publicité en cours de FLE montre qu'elle:

- sert de source de motivationdes apprenants;

- créeun contexte communicatif du fonctionnement des points de langue (grammaire, vocabulaire);

- sert de support de communication pour travailler sur la compréhension orale ou écrite; 
- est le facilitateur pour la prise de la parole des apprenants;

- permet de concilier l'apprentissage de la langue à celui de la civilisation etc.

C'est surtout ce dernier point qui suscite notre intérêt, car la publicité a des enjeux évidents pour l'enseignement explicite de la culture cible. A titre d'exemple, citons L. Porcher (1986) qui souligne que "l'image publicitaire peut exprimer la totalité d'une culture déterminée à un moment historique donné et en un lieu donné". Ou encore B. Cathelet (2001), pour qui "toute publicité offre un modèle de culture". Ch. Cornet (2012), lui, accentue que "la publicité est le miroir de la société et de sa culture".

C'est vrai qu'il est impossible d'imaginer la société contemporaine sans publicité. D'une simple proposition commerciale la publicité est devenue un mécanisme d'influence sur le consommateur. Comme le démontre R. Barthes (1985), la publicité peut séduire sans convaincre, et cependant engager à l'achat par cette seule séduction. Pour faire acheter, la publicité utilise différents moyens en s'adaptant à toute clientèle. Elle n'invente rien, en revanche, elle suit des nouvelles idées et en profite.

Les spécialistes en sociolinguistique distinguentdifférents genres publicitaires parmi lesquels le réclame, la publicité classique, la publicité moderne et la publicité post-moderne (N. EveraertDesmedt 1999).

L'objectif du réclame est d'informer, de valoriser le produit et de donner au consommateur un conseil d'achat. C'est un genre publicitaire dominant au 19 ième siècle, mais qui perdure jusqu'à nos jours. Le réclame s'appuie sur le sens rationnel du client qui devrait satisfaire ses besoins. C'est pour ça que le réclame vante le produit en présentant ses meilleures qualités. Par exemple, la marque des meubles Hygiena conseille d'acheter une de ses cuisinesde haute qualité et pas très cher (Image 1), la marque des produits de beauté Yves Rocher vante la qualité de ses crèmes anti-rides (Image 2) et la marque des produits alimentaires Bjorc conseille de manger ses produits bio pour être en forme (Image 3):

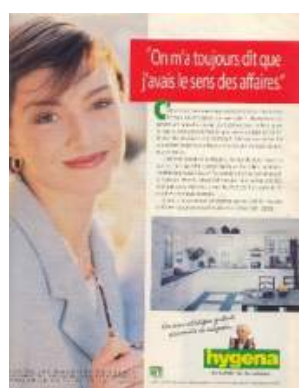

Image 1

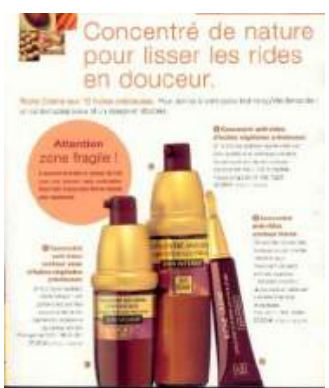

Image 2

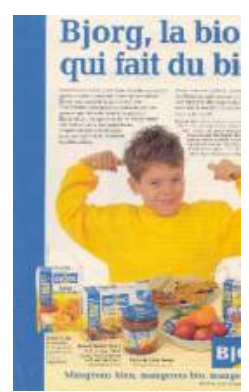

Image 3

L'objectif de la publicité classique est de faire désirer.C'est un genre publicitaire qui s'appuie sur les émotions. Le consommateur est considéré comme passif et guidé. Pour le faire acheter, il faut un stimulus - une belle image, un logo, un slogan. Voilà pourquoi les affiches sont grandes et en couleurs, le slogan se répète à plusieurs reprises. Il n'est pas rare que cette publicité ait recours aux hommes célèbres, stars de cinéma, acteurs, sportifs etc. L'objectif est de faire le consommateur s'associer à une personne célèbre et ainsi de désirer faire pareil, avoir le produit pareil. Par exemple, le footbaleur français Zenadine Zidane et l'actrice Monica Belucci présententdes parfums de Christian Dior (Image 4 et Image 6). Zenadine Zidaneprésente également l'eau minérale Volvic ( Image 5) 


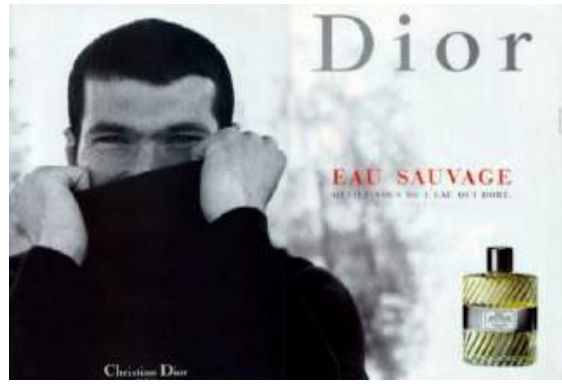

Image 4

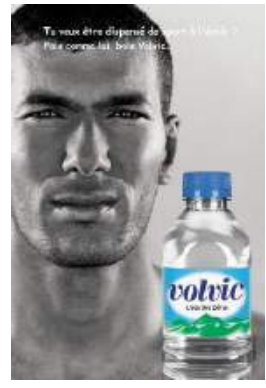

Image 5

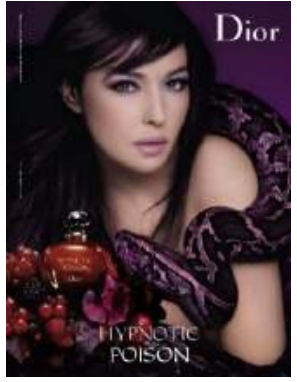

Image 6

L'objectif de la publicité moderne est de faire plaisir. C'est une publicité suggestive qui s'appuie sur les désirs, les fantaisies et l'inconscient du consommateur. Pour cette publicité, le libido et la sexualité sont des moteurs de vente. Le produit est associé à l'erotisme qui apparaît dans les slogans tels que "pour rugir de plaisir" (barre de chocolat Lion) ou "un café nommé désir" (café Carte Noire). Pourtant, les images trop sexuelles de cette publicité font polémique dans la société et sont souvent critiquées au sujet de sexisme (Rousnak 2018). L'exploitation de ce genre publicitaire en classe de FLE est le plus contradictoire et demande de l'enseignant une préparation spéciale.En voici quelques exemples: les pubs pour un appareil de photo Fudjifilm (Image 7), le boisson Schwepes (Image 8) et le jean YanuK (Image 9).

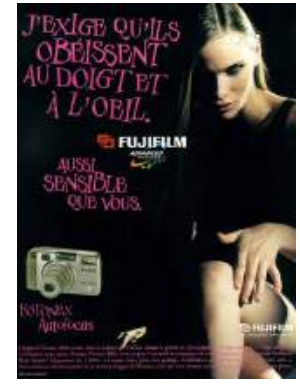

Image 7

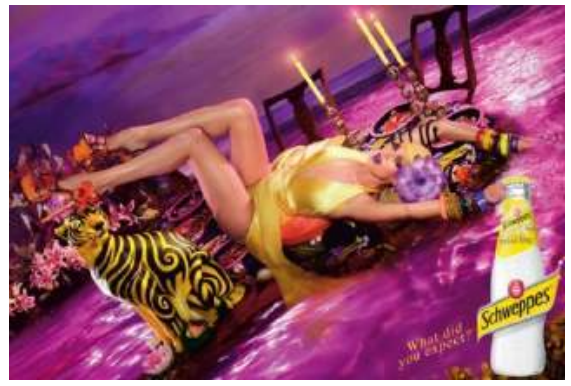

Image 8

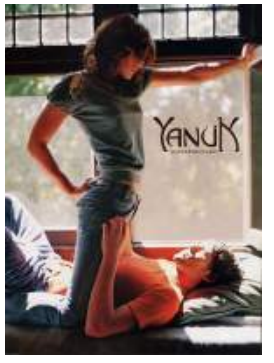

Image 9

L'objectif de la publicité post-moderne est de faire penser. Elle porte sur la morale et la condition humaine en s'adressant aux citoyens du monde. C'est une publicité ethique dont la compagnie Benetton (Images 10 et 11) est un vif exemple. A notre avis, c'est cette publicité qui répond le plus à tous les objectifs de l'enseignement supérieur (communicatif, éducatif, cognitif et (inter)culturel).

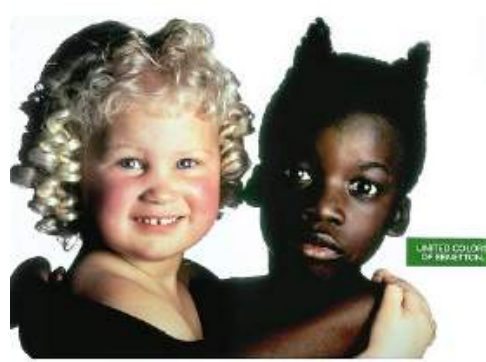

Image 10

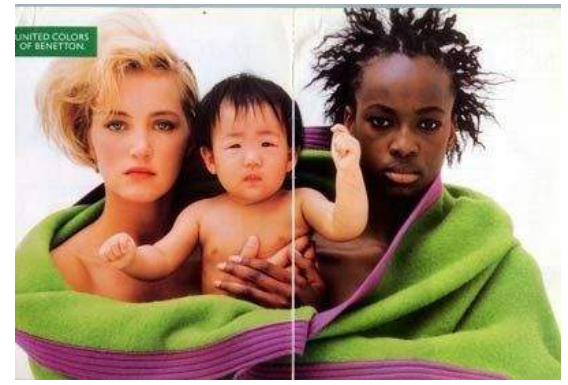

Image 11 
A son tour, G. Lugrin (2006) répartit les genres publicitaire en réclame, publicité de produit, publicité de marque, publicité de connivence et publicité ethique.

D'un point de vue didactique, l'intérêt culturel du réclameen classe de FLE est la prise de connaissance des noms de marques françaises, la présentation des pratiques de la vie quotidienne etc. De plus, grâce au texte assez long, ce genre publicitaire peut servir de support pour le développement de la compréhension écrite en français ainsi que des compétences linguistiques (Images 1-3).

L'intérêt culturel de la publicité de produit est qu'elle fait souvent référence au passéayant recours aux noms de héros, aux personnages historiquesou mythiques, comme, par exemple la publicité du vinaigre Maille qui évoque le roi Louis XIV (Image 12) ou le yaourt Nestlé qui met en scène la Laitière de la Fontaine peinte par Vermeer (Image 13):

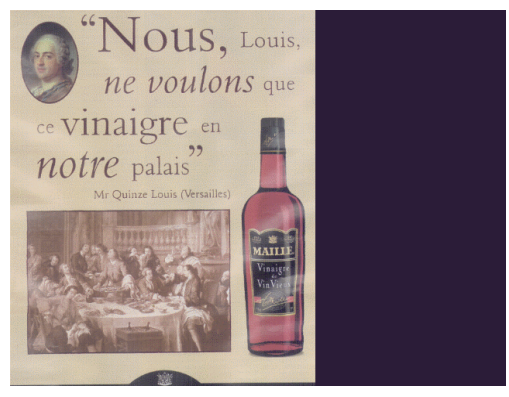

Image 12

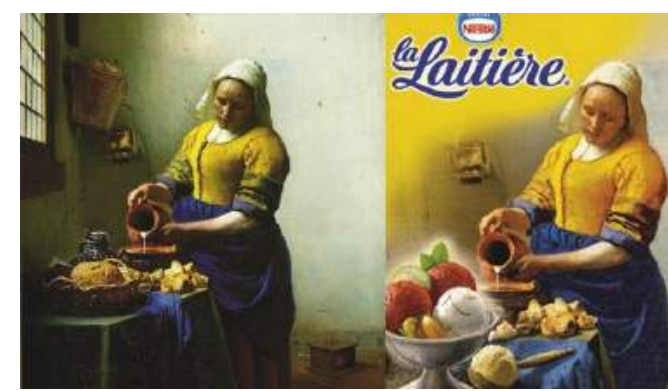

Image 13

La publicité de marque peut, pour acrocher le client et se faire mémoriser, faire référence aux oeuvres d'art, aux personnages littéraires, aux hommes célèbres etc. Ainsi, la compagnie de communication Orange et la marque l'Oréal adoptent les couleurs vives et les formes abstraites de Mondrian (Images 14 et 15); La jeune fille à la perle de Vermeer est maquillée avec du rouge à lèvre de Chanel (Image 16):

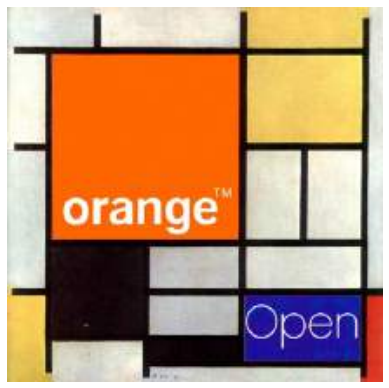

Image 14

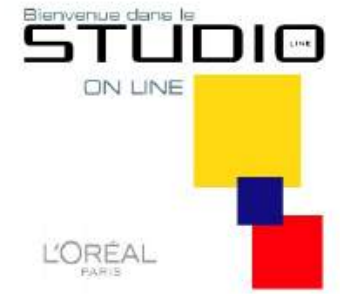

Image 15

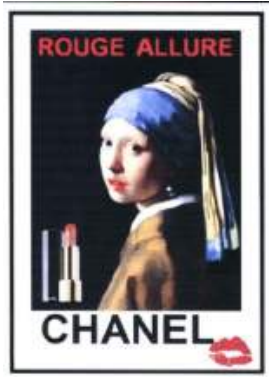

Image 16

Pour sa part, le personnage de conte le Chaperon rouge se sent bien à l'aise dans le taxi Uber (Image 17):

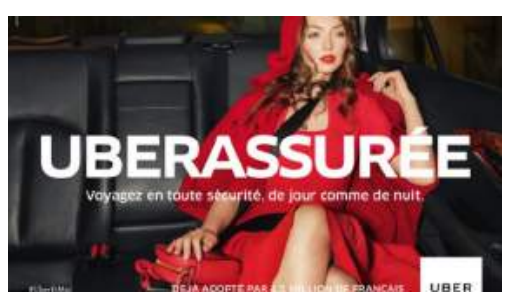

Image 17 
Souvent, la publicité de marque exploite des représentations stéréotypées sur la France et ses habitants. Par exemple, une série d'imagesde la compagnie aérienne Air France illustrent des belles femmes dont le look est associé aux symboles de la France: drapeau bleu blanc rouge (Image 18), la haute couture et la Tour Eilffel (Image 19) et la haute cuisine française (Image 20).

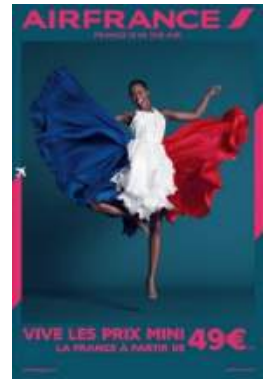

Image 18

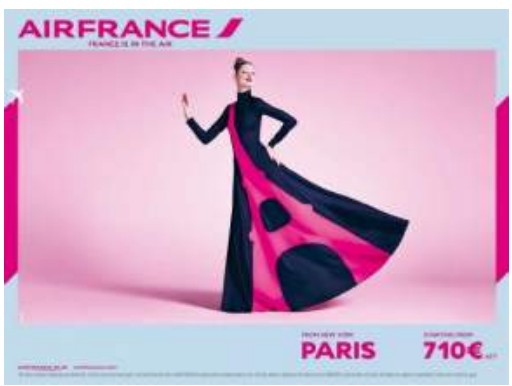

Image 19

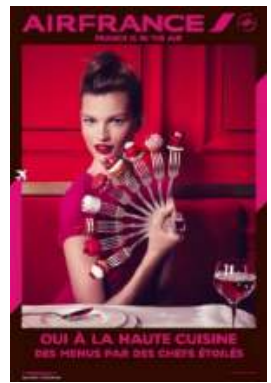

Image 20

La publicité de connivence fait partie de la publicité moderne dont l'objectif est de faire plaisir. Pour ce faire, elle a recours à l'humour comme technique qui évoquerait des émotions positives du client potentiel à l'égard d'un produit ou d'une marque. Ainsi, l'Oréal joue sur les mots homonymiques, en transformant son slogan Parce que je le vaut bien en Parce que je le veau bien, et en mettant en scène une vache aux beaux cheveux blonds (Image 21). Les médicaments Aero digest contre les maux de l'estomac vont encore plus loin en présentant la célèbre Mona Lisa avant et après la consommation de ces médicaments (Image 22):

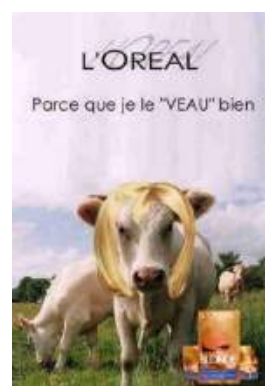

Image 21

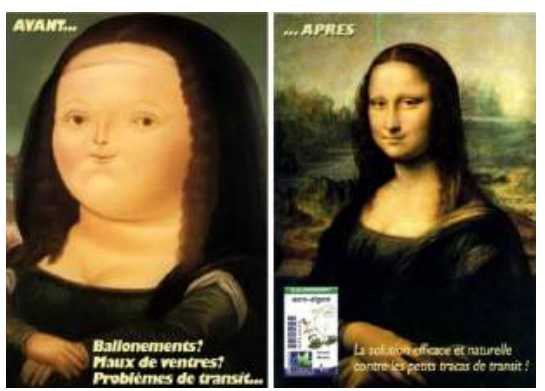

Image 22

En ce qui concerne la publicité ethique, elle a le plus grand intérêt d'être exploitée en classe de FLE comme telle qui met en évidence les problèmes sociaux du monde cible ayant pour objectif de faire penser les gens et de former, de cette manière, des citoyens conscients. De plus, elle aussi a recours aux codes culturels décrits en haut. Par exemple, la Sécurité routière met en scène le couturier réputé Karl Lagerfeld (Image 23) au gilet jaune pour attirer l'attention des automoblistes aux gilets luminiscents qui peuvent sauver la vie sur la route.

Les compagnies Aurore et la Fondation Abbaye Pierre essayent d'attirer l'attention des gens au problème des sans-abris par les slogans qui représentent les expressions connues transformées: Le nom de marque Yves-Saint Laurent en Yves Sans Logement (Image 24); l'expression figée MétroBoulot-Dodo qui représente un rythme quotidien d'un homme qui travaille en Métro-Boulot-Métro (Image 25) cequi veut dire qu'on n'a pas de logement où dormir. 


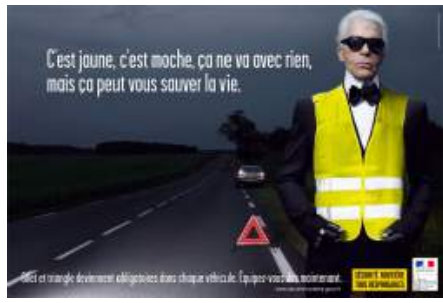

Image 23

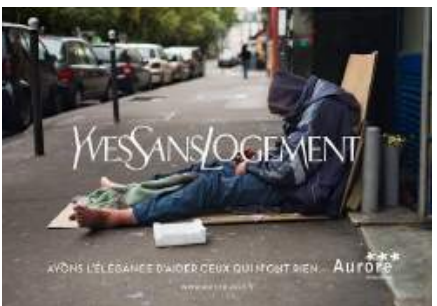

Image 24

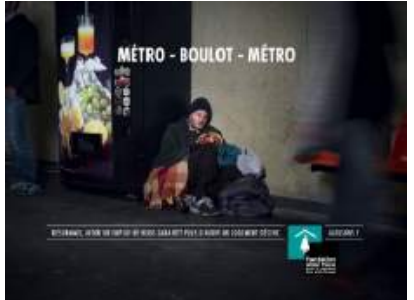

Image 25

Alors, l'analyse de la dimension culturelle de la publicitéiconique fait voir l'exploitation de différents codes culturels tels que présence des hommes connus, personnages historiques ou mythologiques; parodie d'oeuvresd'art; citations des proverbes et expressions figées; images stéréotypées du pays cible et ses habitants etc. En un mot, ce sont les connaissances partagées par les individus d'une société qui peuvent poser,cependant,un obstacle à la compréhension pour un apprenant étranger. Voilà pourquoi, dans la classe de langue, la compréhension de certaines images demande un travail spécial dont nous parlerons dans la suite.

Dans le but de faire comprendre un document publicitaire aux apprenants, nous adoptons l'approche sémiologique de R. Bartes (1963), pour qui toute image publicitaire a trois niveaux d'analyse: 1) niveau linguistique (connaissances d'une langue); 2) niveau iconique (sens dénoté d'une image); 3) niveau symbolique ou culturel (sens connoté d'une image).

Pour analyser la publicité au niveau linguistique, il faut tout simplement connaître la langue. Ici, la compétence linguistique est primordiale.

Pour analyser la publicité au niveau iconique, il faut savoir décoder le sens dénoté d'une image en répondant aux questions de la compréhension globale: Qui voyez-vous sur l'image? Quels objets sont représentés? Comment est la personne vue? etc.

Pour analyser la publicité au niveau symbolique ou culturel, il faut faire l'analyse des associations que font paraître les codes culturels afin de dégager le sens connoté lié à l'image. A quoi cette image fait-elle allusion? A quel phénomène culturel cette image fait-elle référence? C'est à cette étape que les étudiants s'acquèrent les connaissances culturelles qui font partie de la CCI.

Parexemple, dans la publicité du fromage Made in Haute-Savoie (Image 27) on voit le message linguistique Nous, LevMade in France, on y croit! Et le Made in Haute-Savoie encore plus!, le message iconique: le vieux monsieur au béret et au t-shirt rayé qui tient un morceau de fromage, au premier plan, et des montagnes, au fond, et, en fin, le message symbolique: un béret et un t-shirt rayé qui sont associés à la France ainsi que les montagnes qui font référence à la nature, à l'air pur en accentuant ainsi la bonne qualité du produit présenté.

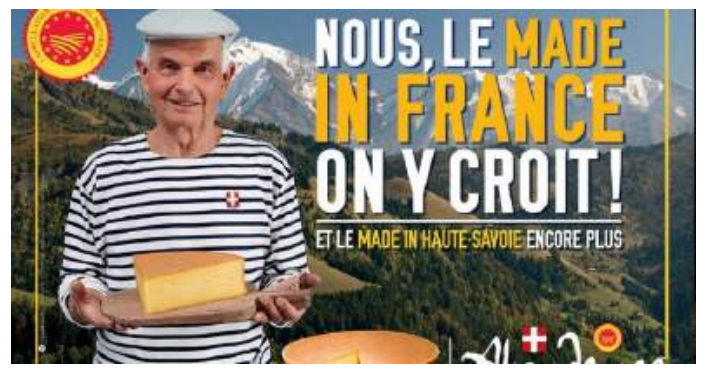

Image 27 
La publicité pour des petits biscuits LU (Image 28) fait allusion à la vie de Van Gogh et à sontableau l'Autoportrait à l'oreille coupée (Image 29). Le message linguistique Hommage à Van Gogh est suivi d'un message iconique: un biscuit entamé sur le coin droit. Le message symbolique fait référence à l'épisode de la vie de Van Gogg où il s'est coupée l'oreille.

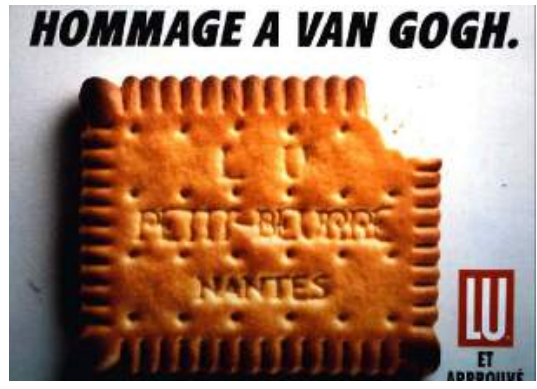

Image 28

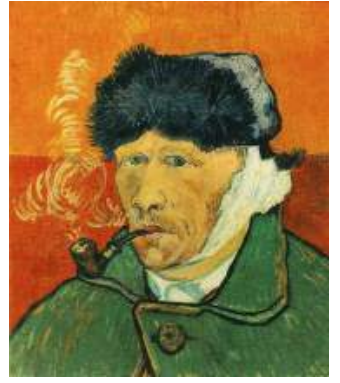

Image 29

Pour comprendre la publlicité de l'Ordre des avocats de Lille dont le message linguistique est Ceci n'est pas un avocat (Image 30) ou du vinaigre balsamique Maille (Image 32) avec trois messages pareils: Ceci n'est pas une coupe de fraises à la crème pour une coupe de fraises à la crème; Ceci n'est pas une assiette de tomates pour une assiette de tomates, Ceci n'est pas un oeuf sur le plat pour un oeuf sur le plat, il faut connaître l'oeuvre de Magritte Ceci n'est pas une pipe (Image 31 ) à laquelle font référence ces publicités.

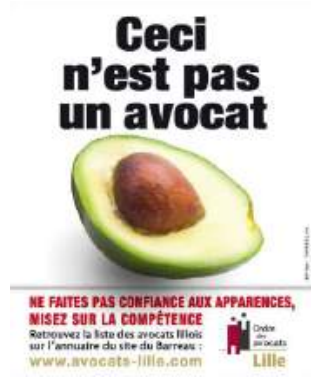

Image 30

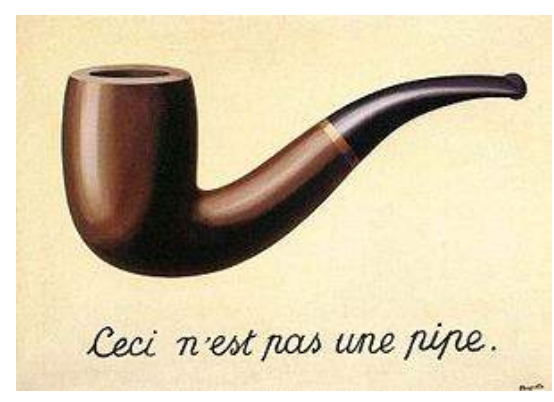

Image 31

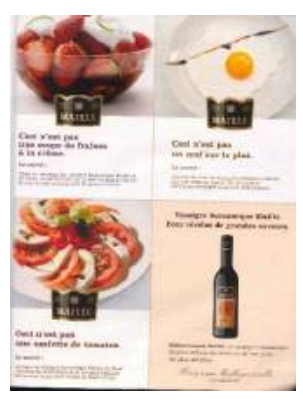

Image 32

La publicité du parfum La petite robe noire de Guerlain (Image 33) a quelques codes culturels: d'une part, l'image de la Tour Eiffel, symbole de la France qui accentue l'origine du produit présenté, et, d'autre part, le nom du parfum qui fait référence à la petite robe noire de Chanel devenue aussi symbole français assocué à la haite couture.

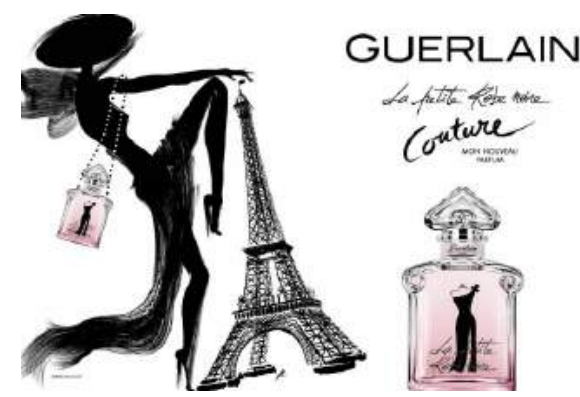

Image 33 
Or, suivre les trois étapes de la démarche sémiologique dans l'analyse de la publicité iconique devrait amener les étudiants à la meilleure compréhension des messages publicitaires favorisant ainsi l'acquisition des connaissances culturelles qui sont essentielles pour développer la conscience interculturelle chez les futurs enseignats de FLE. Après avoir fait comprendre la publicité à tous les niveaux, il est préférable de proposer aux étudiants des tâches à visée interculturelle, par exemple, dans l'élaboration des publicités identiques mais avec les codes culturels de la langue maternelle.

En guise de conclusion notons que la publicité iconique d'origine frnnçaise est de différents genres dont chacun a ses intérêts d'exploitation dans l'enseignement interculturel lors des cours de langue pratiques en première / deuxième années d'apprentissage. Pourant, la moins adaptée au processus d'enseignement / apprentissage serait la publicité moderne qui demanderait de l'enseignant un travail de préparation spécial. La plus adaptée, à notre avis, est la publicité post-moderne (ethique) qui, après la didactisation adéquate, répondrait à tous les objectifs de la formation supérieure.

La perspective des recherches ultérieures consiste dans l'étude plus profonde de la publicité éthique de France et d'Ukraine afin de la faire entrer dans la classe de langue et de diversifier les contenus interculturels en optimisant ainsi le processus du développement de la $\mathrm{CCI}$ chez les futurs enseignants de FLE.

\section{REFERENCES}

Руснак, Д. А. (2005). Соціокультурні аспекти формування граматичної компетенції у майбутніх викладачів французької мови. Вісник КНЛУ. Педагогіка та психологія, 8, 201-206.

Руснак, Д. А. (2015). Формування медіакомпетентності у майбутніх учителів / викладачів французької мови. В О. Б. Бігич (Наук. ред.), Компетентність в аудіюванні майбутнього вчителя іспанської та франиузької мов: теорія і практика формування [колективна монографія], (сc. 90-163). Київ, Україна: Вид. центр КНЛУ.

Руснак, Д. А. (2017). Мобільний кейс “Реклама як засіб формування міжкультурної компетентності: гендерні, вікові й етнічні стереотипи” для майбутніх учителів / викладачів французької мови. В О. Б. Бігич (Наук. ред.), Кейсова і подкаст технологї формування міжкультурної компетентності [колективна монографія] (сс. 22-91). Київ, Україна: Вид. центр КНЛУ.

Rousnak, D. (2018). Les contenus spécifiques del'enseignement interculturel de futurs enseignants de FLE: stéréotypes de genre. Вісник КНЛУ. Педагогіка та психологія, 28, 133-142.

Barthes, R. (1964). Rhétorique de l'image. Communications, Recherches sémiologiques, 4, 40-51.

Bartes, R. (1985). Le message publicitaire. L'aventure sémiologique (pp. 243-248). Paris, Éditions du Seuil.

Byram, M. Gribkova, B., Starkey, H. (2002). Développer la dimension interculturelle dans l'enseignement des langues: une introduction pratique à l'usage des enseignants. Strasbourg, Conseil de l'Europe.

Catelet, B. (2001). Publicité et Société. Paris, Payot: Petite Bibliothèque Payot.

Cornet, Ch. (2012). La pub, miroir de notre société. Vivre Ensemble. Education. Bruxelles.

Everaert-Desmedt, N. (1999). Magritte au risque de la sémiotique (pp. 87-109). Bruxelles, Publications des facultés universitaires Saint-Louis.

Lázár, Il., Huber-Kriegler, M. (2007). Développer et évaluer la compétence en communication interculturelle : Un guide à l'usage des enseignants de langues et des formateurs d'enseignants. Strasbourg, Editions du Conseil de l'Europe.

Lugrin,G. (2006). Généricité et intertextualité dans le discours publicitaire de presse écrite. Publications universitaires européennes. Berlin, Peter Lang SA, Editions scientifiques internationales.

Porcher, L. (1986). La civilisation. Paris, Clé international. 


\section{REFERENCES}

Rusnak, D. A.(2005). Sociokul turni aspekty` formuvannya gramaty chnoyi kompetenciyi u majbutnix vy kladachiv franczuz koyi movy`. Visny 'kKNLU. Pedagogikatapsy`xologiya, 8, 201-206.

Rusnak, D. A. (2015). Formuvannya mediakompetentnosti u majbutnix uchy`teliv / vy`kladachiv franczuz koyi movy. V O. B. Bihych (Nauk. red.), Kompetentnist` v audiyuvanni majbutn’ogo vchy`telya ispans'koyi ta franczuz koyi mov: teoriya i prakty`ka formuvannya [kolektyvna monohrafiia] (ss. 90-163). Kyiv, Ukraina: Vyd. Tsentr KNLU.

Rusnak, D. A. (2017). Mobil'nyj kejs "Reklama iak zasib formuvannia mizhkul'turnoi kompetentnosti: henderni, vikovi j etnichni stereotypy" dlia majbutnikhuch yteliv / vykladachiv frantsuz'koi movy. V O. B. Bihych (Nauk. red.), Kejsova i podkast tekhnolohii formuvannia mizhkul'turnoi kompetentnosti [kolektyvna monohrafiia] (ss. 22-914). Kyiv, Ukraina: Vyd. tsentr KNLU.

Rousnak, D. (2018). Les contenus spécifiques del'enseignement interculturel de futur senseignants de FLE: stéréotypes de genre. Visny'k KNLU. Pedagogikataps y’xologiya, 28, 133-142.

Barthes, R. (1964). Rhétorique de l'image. Communications, Recherches sémiologiques, 4, 40-51.

Bartes, R. (1985). Le message publicitaire. L’aventure sémiologique (pp. 243-248). Paris, Éditions du Seuil.

Byram, M. Gribkova, B., Starkey, H. (2002). Développer la dimension interculturelle dans l'enseignement des langues: une introduction pratique à l'usage des enseignants. Strasbourg, Conseil de l'Europe.

Catelet, B. (2001). Publicité et Société. Paris, Payot: Petite Bibliothèque Payot.

Cornet, Ch. (2012). La pub, miroir de notre société. Vivre Ensemble. Education. Bruxelles

Everaert-Desmedt, N. (1999). Magritte au risque de la sémiotique (pp. 87-109). Bruxelles, Publications des facultés universitaires Saint-Louis.

Lázár, Il., Huber-Kriegler, M. (2007). Développer et évaluer la compétence en communication interculturelle : Un guide à l'usage des enseignants de langues et des formateurs d'enseignants. Strasbourg, Editions du Conseil de l'Europe.

Lugrin, G. (2006). Généricité et intertextualité dans le discours publicitaire de presse écrite. Publications universitaires européennes. Berlin, Peter Lang SA, Editions scientifiques internationales.

Porcher, L. (1986). La civilisation. Paris, Clé international. 